\section{The American Board of Thoracic Surgery}

\section{Notices}

$\mathrm{T}$ he part I (written) examination was held on December 3. It is planned that this examination will be given at multiple sites throughout the United States using an electronic format. The closing date for registration is August 1 each year. Those wishing to be considered for examination must apply online at www.abts.org.

To be admissible for the Part II (oral) examination, a candidate must have successfully completed the Part I (written) examination.

A candidate applying for admission to the certifying examination must fulfill all the requirements of the Board in force at the time the application is received. Please address all communications to the American Board of Thoracic Surgery, 633 North St Clair Street, Suite 2320, Chicago, IL 60611 (telephone: 312-2025900).

\section{Requirements for Maintenance of Certification}

$\mathrm{D}$ iplomates of the American Board of Thoracic Surgery (ABTS) who plan to participate in the Maintenance of Certification (MOC) process must hold an unrestricted medical license in the locale of their practice and privileges in a hospital accredited by the JCAHO (or other organization recognized by the ABTS). In addition, a valid ABTS certificate is an absolute requirement for entrance into the Maintenance of Certification process. If your certificate has expired, the only pathway for renewal of a certificate is to take and pass the Part I (written) and the Part II (oral) certifying examinations.

The names of individuals who have not maintained their certificate will no longer be published in the American Board of Medical Specialties Directories. Diplomates' names will be published upon successful completion of the Maintenance of Certification process.
The CME requirements are 30 Category I credits earned during each year prior to application. At least half of these CME hours need to be in the broad area of thoracic surgery. Category II credits are not allowed. Interested individuals should refer to the Booklet of Information for Maintenance of Certification for a complete description of acceptable CME credits. Diplomates will be expected to submit verification of CME earned.

Diplomates in the Maintenance of Certification process will need to provide a summary of their major cases performed during the year prior to application. The practice review should not exceed 100 cases.

Diplomates in the Maintenance of Certification process will be required to complete all sections of the SESATS self-assessment examination. It is not necessary for Diplomates to purchase SESATS individually, because it will be sent to them after their application has been approved.

Diplomates may apply for Maintenance of Certification in the year their certificate expires, or if they wish to do so, they may apply up to two years before it expires. However, the new certificate will be dated 10 years from the date of expiration of their original certificate or most recent recertification certificate. In other words, going through the Maintenance of Certification process early does not alter the 10-year validation. Diplomates certified prior to 1976 (the year that time-limited certificates were initiated) are also required to participate in MOC if they wish to maintain valid certificates.

The deadline for submission of application for the Maintenance of Certification is May 10 of each year. All ABTS diplomates will receive a letter from the Board outlining their individual timeline and MOC requirements. A brochure outlining the rules and requirements for Maintenance of Certification in thoracic surgery is available upon request from the American Board of Thoracic Surgery, 633 North St. Clair Street, Suite 2320, Chicago, IL 60611; telephone (312) 202-5900; fax (312) 202-5960; email info@abts.org. This booklet is also published on the website: www.abts.org. 